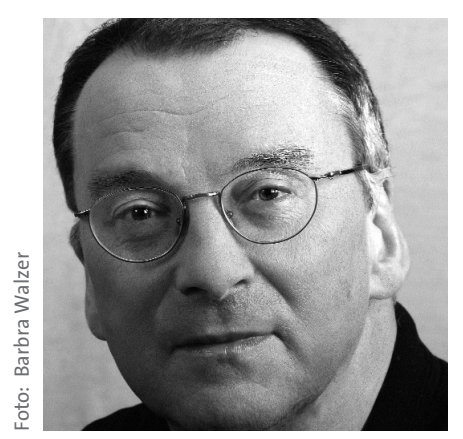

\title{
Zwischen Ethik und Wirtschaftlichkeit
}

Wohlfahrtsverbände und Sozialunternehmen sehen sich unter Beschuss. Von »Hilfsindustrie «(so der «Stern « 8/2011) ist die Rede und von »kapitalistischen Musterbetrieben «, denen nichts wichtiger sei, als Umsätze zu steigern, Kapazitäten auszulasten, neue Märkte zu erschließen, Konkurrenten zu verdrängen und immer mehr Behinderte für den geschlossenen Verwertungskreislauf von der Frühförderung bis zur Werkstatt zu akquirieren (so die »tageszeitung " am 15. Juli 2011). Prof. Dr. Andreas Strunk hat in der vorigen Ausgabe dieser Zeitschrift auf solche Anschuldigungen bereits in sieben schlüssigen Argumenten geantwortet (SOZIALwirtschaft 4/2011).

Doch trifft die sich mehrende Kritik von außen durchaus auf Zweifel auch im Innern der Branche. Sind nicht einige soziale Organisationen und Unternehmen bei dem Bestreben nach mehr Wirtschaftlichkeit gelegentlich über das Ziel hinausgeschossen? Der marktorientierte Umbau der Sozialen Arbeit bei der »Modernisierung des Sozialstaates « habe zur Übernahme betriebswirtschaftlicher Managementkonzepte durch die Sozialwirtschaft geführt, stellen Dr. Eva Douma und Dr. Frank-Olaf Brauerhoch in ihrem Einleitungsbeitrag in diesem Heft fest und weisen auf die Problematik dieser Entwicklung hin: Die Angleichung an die Methoden der Profitwirtschaft könne die Sozialwirtschaft als eigenem Sektor mit spezifischen Charakteristika und daraus resultierenden Aufgaben delegitimieren.

Ein besonderes Merkmal insbesondere der Freien Wohlfahrtspflege war es, Bürgerinnen und Bürger für soziale Gemeinwohlaufgaben zu gewinnen. Privatisierung und Ökonomisierung bringen jedoch die Gefahr mit sich, soziale Einrichtungen nur noch als reine Dienstleister zu betrachten. Gemeinwesenbezogene Ambitionen über das eigene Fachgebiet hinaus könnten verloren gehen, warnt Dr. Brigitte Reiser in ihrem Artikel in dieser Ausgabe. Dabei könnten, so ihr Hinweis, soziale Organisationen durch die Beteiligung von Bürgerinnen und Bürgern manches hinzugewinnen: Geld, Sachgüter, Wissen, Mitarbeit, politische Unterstützung, Vertrauen. 